Annales Geophysicae (2003) 21:221-236 (C) European Geosciences Union 2003



\title{
High resolution nested model for the Cyprus, NE Levantine Basin, eastern Mediterranean Sea: implementation and climatological runs
}

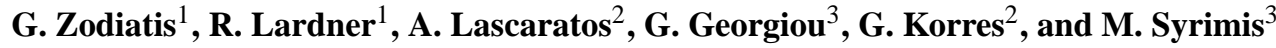 \\ ${ }^{1}$ Oceanography Section, Department of Fisheries and Marine Research, Nicosia, Cyprus \\ ${ }^{2}$ Oceanography group, Department of Meteorology, University of Athens, Athens, Greece \\ ${ }^{3}$ Department of Mathematics and Statistics, University of Cyprus, Nicosia, Cyprus
}

Received: 28 May 2001 - Revised: 14 June 2002 - Accepted: 17 June 2002

\begin{abstract}
A high resolution nested flow model for the coastal, shelf and open sea areas of the Cyprus Basin, NE Levantine, eastern Mediterranean Sea is implemented to fulfil the objectives of the Mediterranean Forecasting System Pilot Project, funded by the EU. The Cyprus coastal ocean model is nested entirely within a coarse regional grid model of the eastern Mediterranean Sea, using the MODB climatology for initialisation and the ECMWF perpetual year surface forcing. The nested simulations of the Cyprus model were able to reproduce, with greater detail, flow features similar to those of the coarse grid regional model. The project results show the feasibility of the approach for the development of an operational forecasting system in the Mediterranean Sea, particularly in the Cyprus coastal/shelf sea area.
\end{abstract}

Key words. Oceanography: general (descriptive and regional oceanography; numerical modelling) Oceanography: physical (general circulation)

\section{Introduction}

Knowledge of sea water movements is of importance in forecasting the effects of human activities on the marine environment. Today, flow modelling is considered a necessary operational tool, useful to aid decision-making in case of events affecting marine operations or the marine environment. In this regard, the European Global Ocean Observing System (EuroGOOS, 1997) has promoted the Mediterranean Forecasting System (MFS), in order to implement the operational oceanography in the region. The first phase in the realization of this goal is the development of the Mediterranean Forecasting System Pilot Project (MFSPP) funded by the EU, in order to demonstrate that a Near Real Time (NRT) ocean forecast in the Mediterranean Sea is possible.

The scientific rationale of the MFS pilot project is based on the hypothesis that both hydrodynamical and ecosystem fluctuations in the coastal/shelf areas of the Mediterranean

Correspondence to: G. Zodiatis (gzodiac@ucy.ac.cy) are intimately connected to the open sea large-scale general circulation. The project includes the implementation of advanced modelling and data assimilation tools for NRT prediction. The oceanographic prediction models of the first phase are (Fig. 1):

- An Ocean General Circulation Model (OGCM) with $1 / 8 \times 1 / 8$ degree resolution over the whole Mediterranean Sea.

- Several Intermediate/Regional Models nested within the OGCM. The intermediate models have a $5-6 \mathrm{~km}$ resolution.

- One or more coastal/shelf models nested within each regional model. The shelf models have a $2-3 \mathrm{~km}$ resolution.

The Cyprus Coastal Ocean Model (CYCOM) is one of the coastal/shelf models of the MFS pilot project, for high resolution flow simulations in the Cyprus and the NE Levantine basins. It is nested within the Aegean Levantine Eddy Resolving Model (ALERMO), which covers the whole eastern portion of the Mediterranean Sea. In this paper, we present results for the seasonal variability of the circulation in the Cyprus Basin based on the ECMWF perpetual year surface forcing. Both CYCOM and ALERMO use numerical schemes that are modified versions of POM (the Princeton Ocean Model). The POM model has been widely used both within the framework of the MFSPP and elsewhere, to simulate the flows in both regional and coastal/shelf sea areas of the Mediterranean Sea.

In Sect. 2 of the paper, we shall briefly review the oceanographic features of the Cyprus Basin and Levantine. In Sect. 3, we shall give the equations that provide the basis of the model and shall present the numerical algorithm for computing their solution. We shall describe the Cyprus model domain along with the treatment of the boundary data for nesting. In Sect. 4, we shall discuss some numerical results over the area of interest. 


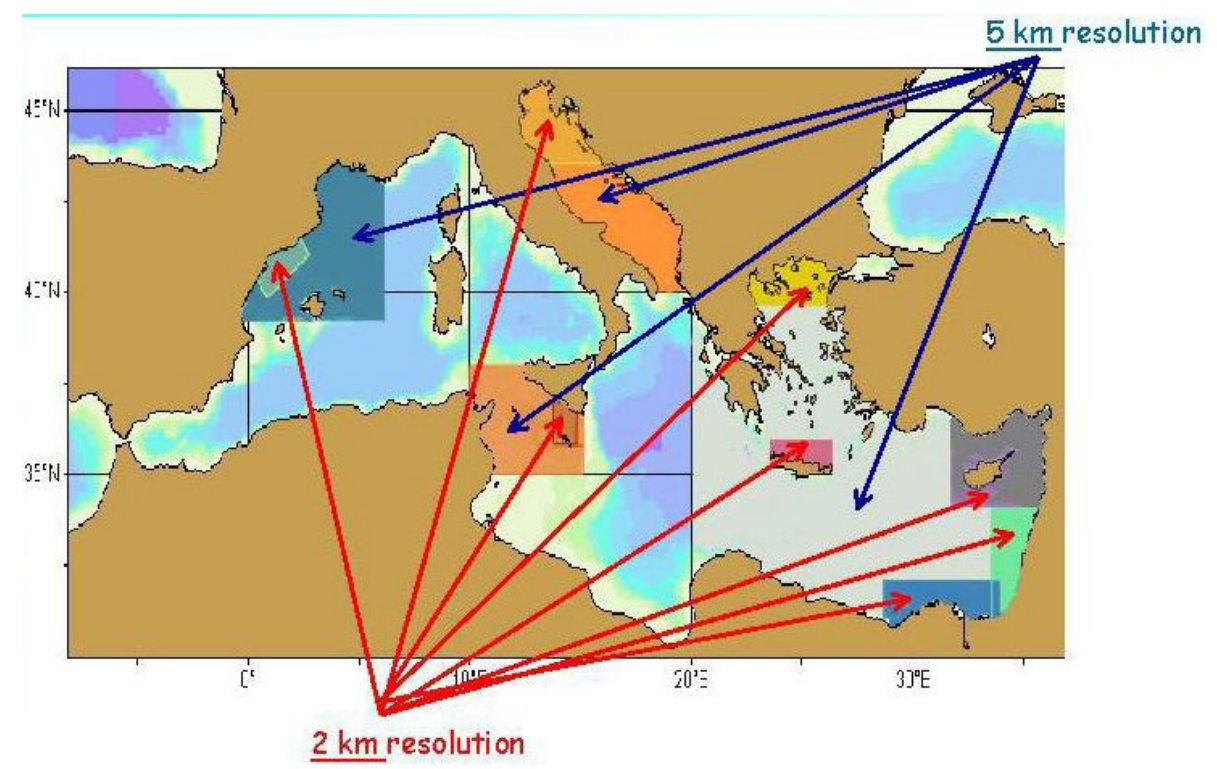

Fig. 1. High resolution simulations in the Mediterranean Sea with nested model and implementations: regional and shelf models of the MFSPP project.

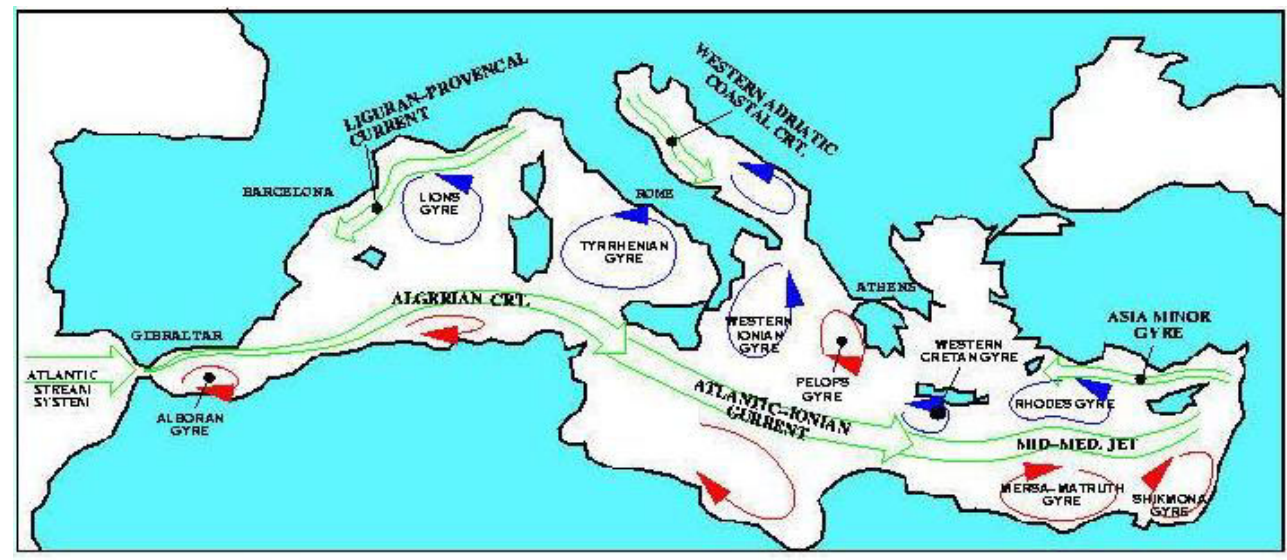

Fig. 2. Schematic of the main features of the general circulation in the Mediterranean, after Roussenov et al. (1995).

\section{Known features of the general circulation}

Progress in the definition of the circulation in the eastern Mediterranean Sea has come both from observational campaigns and numerical modelling (Fig. 2). The general flow picture in the Levantine Basin, derived from the observational experiments (Brenner, 1989; Ozsoy et al., 1989; Ozsoy et al., 1991; POEM group, 1992), was shown to be dominated by the cyclonic activity of the Rhodes gyre in the northwestern part of the region, the Mersa Matruch and Shikmona anticyclonic gyres in the southern part of the basin, the mid-Mediterranean jet (MMJ) and the Asia Minor current (AMC) in the Cilician Basin. Generally, the MMJ meanders eastward between these three gyres. To the southwest of Cyprus this current bifurcates, with a northward flowing branch along the western coast of Cyprus. The eastward flowing branch of the MMJ, after passing south of Cyprus, bifurcates generally to the north, where after pass- ing through the Lattakia Basin, enters the Cilician Basin and then flows to the west between a sequence of smaller scale cyclonic and anticyclonic eddies. The latter flow initiates the Asia Minor Current, which transfers warm and salty water (39.2-39.4 PSU) to the west (Ozsoy et al., 1989), and partially enters into the Aegean Sea through the eastern Cretan arc straits.

Knowledge of the smaller mesoscale eddies is crucial to understanding the regional circulation at the easternmost boundary of the Mediterranean. The overall picture derived from recent observations of the southeast Levantine Basin carried out seasonally within the framework of the Cyprus Basin Oceanography (CYBO) project from 1995 to 2001 (Zodiatis et al., 1998a; Zodiatis et al., 1998b; Zodiatis et al., 2001) has revealed a new mesoscale flow feature not mentioned previously, the Cyprus Basin Cyclonic Eddy, a flow feature with dimensions of the order of about $50 \mathrm{~km}$ which modifies the eastward movement of the MMJ. Moreover, the 


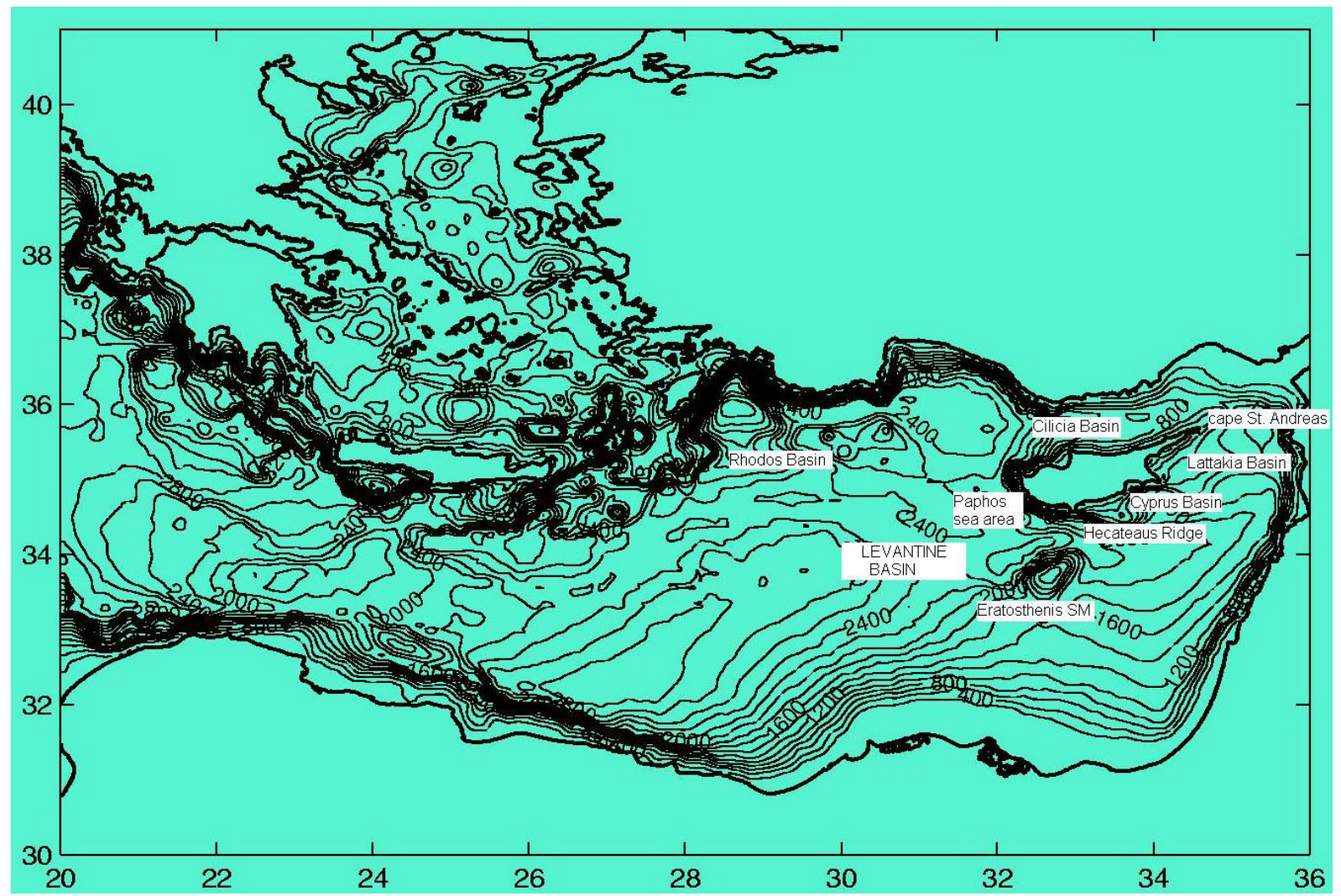

Fig. 3. Physiography and bathymetry of the eastern Mediterranean Sea. In the Levantine Basin some geographical names relevant to the nested CYCOM model for the Cyprus and NE Levantine basins are also shown.

CYBO database reveals a warm westward coastal flow that periodically intrudes the Cyprus Basin along the northern periphery of the Cyprus Basin Cyclonic Eddy from the western Lattakia Basin. The dominant flow phenomenon in the southern Cyprus Basin is the large-scale anticyclonic eddy that is attributed to the Cyprus anticyclonic eddy. This eddy was considered by the POEM group (1992) as the northernmost extension of the large Shikmona gyre. The significant seasonal and interannual fluctuation of the Cyprus anticyclonic eddy affects the spatial extent of the Cyprus Basin Cyclonic Eddy, the eastward meandering flow of the MMJ and the intrusion of the warm Cyprus coastal current.

It is well-known that the general circulation in the Mediterranean Sea is induced both by wind stress at the sea surface and water density differences. The latter are established by such processes as heat fluxes, evaporation, precipitation and exchange with connected water bodies. The use of monthly and seasonal surface fluxes for several years in a coarse grid flow model of the Mediterranean Sea (Roussenov et al., 1995; Pinardi et al., 1997; Drakopoulos and Lascaratos, 1999) has shown a significant seasonal and interannual variation of the circulation at the upper layer, caused primarily by variations in the wind stress. The coastal/shelf areas of the Mediterranean are mostly dominated by the mesoscale flow phenomena of the neighbouring deep regions as they adjust to the physiographic characteristics of each coastal sea area.
The latter is especially true in the case of the Cyprus sea area, which has very narrow coastal areas, steep topographic gradients of the shelf breaks and an open shoreline (Fig. 3).

\section{Description of the model}

CYCOM (Cyprus Coastal Ocean Model) and ALERMO (Aegean Levantine Eddy Resolving Model) are versions of the Princeton Ocean Model (POM), a 3-D circulation model which has been extensively described in the literature (Blumberg and Mellor, 1987; Lascaratos and Nittis, 1998; Zavatarelli and Mellor, 1995). The CYCOM and ALERMO models are used, respectively, for the fine and coarse grid domains in the Levantine Basin. The POM model is a primitive equation, ocean hydrodynamic model based on the equations of momentum and mass conservation and their depth averaged forms. The model comprises a bottom-following sigma coordinate system, a free surface, and split mode time steps. The horizontal viscosity and diffusion terms are evaluated using the Smagorinsky (1963) horizontal diffusion formulation, while the vertical mixing coefficients for momentum and tracers are computed according to the Mellor-Yamada 2.5 turbulence closure scheme (Mellor and Yamada, 1982). Heat and salinity transport sub-models are included. Poten- 


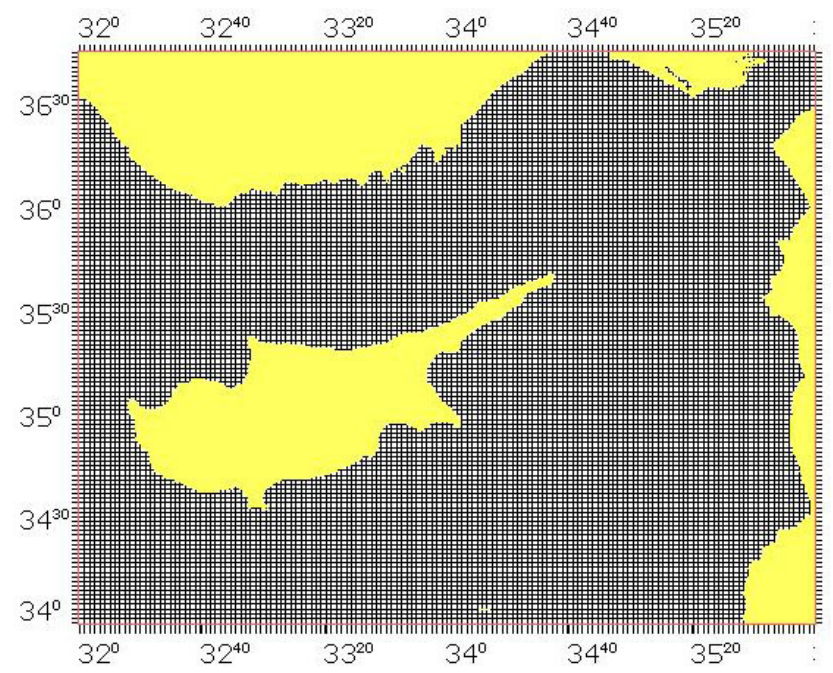

Fig. 4. CYCOM-Cyprus coastal ocean model domain with a horizontal resolution of $3 \times 3 \mathrm{~km}$ and 30 vertical layers from the surface down to $2500 \mathrm{~m}$.

tial temperature, salinity, velocity and surface elevation, are the prognostic variables of the model.

\subsection{Model domain and initial data}

The term Cyprus Basin, or NE Levantine Basin, is used generally to indicate the northeastern end of the Mediterranean Sea and for the sake of precision, we have taken it as that part that is east of the $32^{\circ} \mathrm{E}$ meridian and north of the $34^{\circ} \mathrm{N}$ parallel. Figure 3 shows the general physiography, as well as the bathymetry of this region. The Cyprus model domain is covered by a uniform horizontal orthogonal grid with $3 \mathrm{~km}$ spacing in both the east-west and north-south directions (Fig. 4). The bottom topography is based on the $1^{\prime} \times 1^{\prime}$ high resolution NOAA (National Oceanic and Atmospheric Administration) charts. After being objectively analyzed onto the Cyprus model grid, the depth values vary from surface down to $2500 \mathrm{~m}$.

The requirement for the high resolution CYCOM model is that it should be capable of resolving scales associated with mesoscale phenomena, such as fronts and eddies. Their temporal scales are usually of the order of weeks to months, while their length scales are of the order of the local internal Rossby radius of deformation, which for the Levantine Basin is of the order of about $10-15 \mathrm{~km}$ (POEM group, 1992). It was considered that the chosen model grid size of $3 \mathrm{~km}$ is sufficiently shorter than this local radius of deformation to meet the requirement. It is also sufficient to resolve the steep bathymetry of the sea area west of Cyprus, in addition to defining quite well the rest of the model domain (such as the Cyprus, Lattakia and Cilicia Basins and the Hecateaus Ridge and the shelf areas around Cyprus).

The CYCOM model domain is approximately $440 \times 300 \mathrm{~km}$ in extent, enclosing the island of Cyprus and consists of $146 \times 122$ horizontal grid points with two open boundaries, to the west and to the south (Fig. 4). In the vertical, a non-uniform grid of $30 \sigma$ layers was used with exponentially decreasing spacing near the surface and sea bed to provide finer resolution of the surface and bed layers. The precise geographical limits of the model domain are: Longitude: $32^{\circ} 00^{\prime}-36^{\circ} 00^{\prime}$, Latitude: $34^{\circ} 00^{\prime}-36^{\circ} 45^{\prime}$.

The CYCOM model was initialized on 1 January with the temperature and salinity data from the second year of a twoyear run of ALERMO data, after these data were objectively analyzed to suit the Cyprus domain. To derive the initial data on 1 January, data for 30 December and 10 January were extracted, objectively analyzed and interpolated. In addition, the monthly mean surface temperature and salinity climatology $\left(\mathrm{T}^{*}\right.$ and $\mathrm{S}^{*}$ ) from the second year of the ALERMO run was objectively analyzed and used for the surface relaxation of the heat and salt fluxes, as described below.

The ALERMO model covers the eastern Mediterranean Basin with one open boundary located at $20^{\circ} \mathrm{E}$ (Korres and Lascaratos, 2001a). The computational grid has a horizontal resolution of $1 / 20^{\circ} \times 1 / 20^{\circ}$ and a vertical discretisation using the same $30 \sigma$ layers as CYCOM.

Both the surface forcing and the lateral boundary conditions are re-calculated interactively at each internal time step. The monthly ECMWF perpetual year atmospheric forcing used is based on the re-analyzed data with a spatial resolution of $1^{\circ} \times 1^{\circ}$ for the period January 1979-December 1993, while the back radiation for the CYCOM model was pre-computed by the ALERMO. In general, the monthly wind stress, solar radiation, evaporation and precipitation data were estimated to suit both the regional model and all the coastal/shelf models in the eastern Mediterranean, including the CYCOM model. The Budyko (1963) scheme and the Bignami (1995) formula for heat fluxes, the Jaeger (1976) precipitation and the polynomial approximation, given by Hellerman and Rosenstein (1983), for calculating the wind drag coefficient as a function of wind speed and the differences between air-sea temperature were used for the precomputation of the surface forcing parameters (Korres and Lascaratos, 2001b).

Monthly variations in the heat flux components at the two locations within the Cyprus model domain, NE Levantine Basin (SW and NE areas) shown in Fig. 5. The monthly cycle of the surface forcing parameters showed a maximum downward heat flux during June-July, while during early winter a maximum heat loss occurs. The maximum monthly total heat flux through the sea surface is found to exceed $200 \mathrm{~W} / \mathrm{m}^{2}$ with a minimum value of about $-200 \mathrm{~W} / \mathrm{m}^{2}$.

\subsection{Main characteristics of the numerical model}

1. Nonlinear equations of momentum.

2. Sigma coordinate system in the vertical.

The advantage of this system is that the coordinates follow the bathymetry with the surface and bottom corresponding to uniform values of the vertical coordinate ( $\sigma=0$ at the sea surface and $\sigma=-1$ at the bottom); 


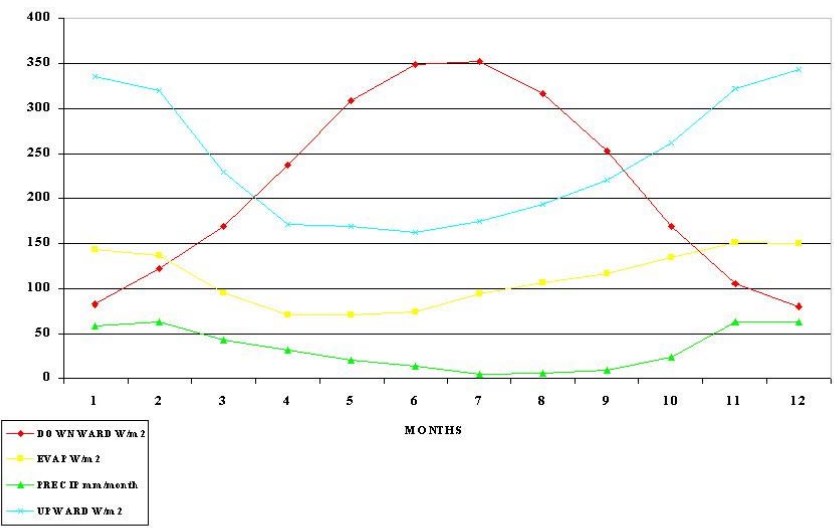

Fig. 5a. ECMWF surface forcing in the NE CYCOM model domain: annual cycle of downward and upward heat fluxes, precipitation and evaporation.

thus, lateral boundary conditions at points where grid level surfaces meet the sea bottom are avoided. Its disadvantage is that an additional term, i.e. the gradient of bottom topography, is introduced into the pressure gradient. Prior to the finite-difference approximation of this term, the bathymetry is smoothed, in order to minimize any truncation error that may be caused by steep topography. Sufficient smoothing is used to eliminate small-scale oscillations in the computed solution while maintaining the essential features of the bathymetry.

3. Time-splitting

The numerical algorithm is based on a splitting method: at each time step, the surface elevation and vertically integrated mass transports (that is, the barotropic mode) are computed from the depth-averaged equations by an explicit leapfrog scheme. Then the vertical structure of the current (baroclinic mode) is obtained from the horizontal momentum equations with a longer time step (Lardner and Cekirge, 1988). The main advantage of such a splitting algorithm is that the time step for advancing the baroclinic mode can be large, since an implicit scheme is used for the vertical part of this mode and this scheme is, in theory, unconditionally stable. The time step, $\tau$, for the barotropic mode is restricted by the CFL stability condition, which is approximately $\tau<\delta / \sqrt{2 g H_{\max }}$, where $\delta$ is the grid spacing and $H_{\max }$ is the maximum depth. However, a fast explicit algorithm is used for this part. Advancing the baroclinic mode is computationally much more demanding and the use of a longer time step for it makes the overall computational scheme quite efficient. In the present CYCOM model domain, the time step for the external mode is $5 \mathrm{~s}$, limited by the $3 \mathrm{~km}$ grid size and the maximum water depth of $2500 \mathrm{~m}$, while the time step for the internal mode is $450 \mathrm{~s}$.

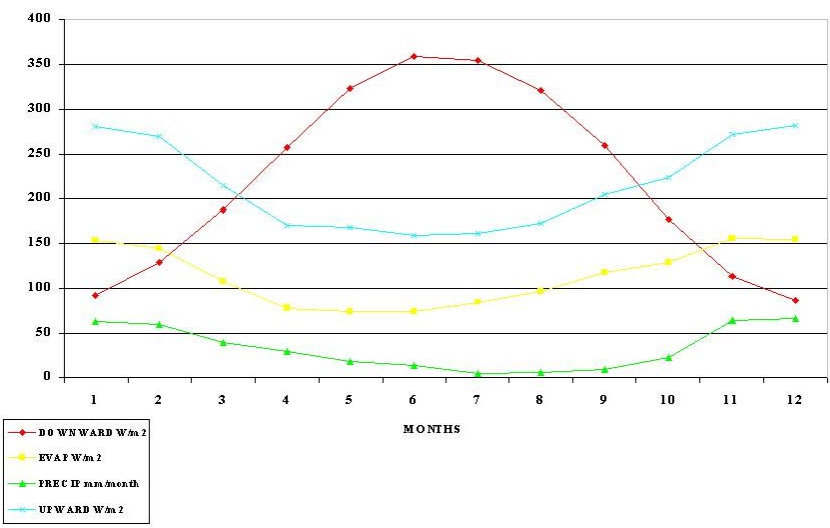

Fig. 5b. ECMWF surface forcing in the SW CYCOM model domain: annual cycle of downward and upward heat fluxes, precipitation and evaporation.

4. Horizontal Cartesian coordinates in the Mercator projection with C-grid (Arakawa and Lamb, 1974).

5. All sub-grid-scale phenomena are considered as mixing processes by introducing separate horizontal and vertical mixing terms:

(a) The horizontal mixing is modelled by an eddy viscosity defined by the scheme of Smagorinsky (1963), in terms of the grid size and the horizontal gradient of the velocity field,

$$
\begin{aligned}
A_{M} & =C \Delta x \Delta y \\
& \cdot \sqrt{\left(\frac{\partial u}{\partial x}\right)^{2}+\left(\frac{\partial v}{\partial y}\right)^{2}+\frac{1}{2}\left(\frac{\partial u}{\partial y}+\frac{\partial v}{\partial x}\right)^{2}}
\end{aligned}
$$

with coefficient $C=0.2$.

(b) The vertical eddy viscosity, a measure of the rate of momentum diffusion through the vertical, is treated by a second order-turbulence closure sub-model (Mellor and Yamada (1982)).

6. Fully prognostic mode.

The time evolution of the temperature and salinity fields is followed and the resultant time-dependent density field is used to compute the baroclinic forcing terms.

It is worth mentioning that the original POM code of the sea water equation of state used to calculate the water density in subroutine DENS was modified to compute $(\rho-1000)$ rather than $\rho$. This simple change gains two orders of magnitude in accuracy in the computed density gradient. Otherwise, if the code is run in single precision as coded, most of the significant part of the density gradient will be lost. 


\subsection{Equations of the model}

Baroclinic mode continuity and horizontal momentum equations:

$$
\begin{aligned}
& \frac{\partial D u}{\partial x}+\frac{\partial D v}{\partial y}+\frac{\partial \omega}{\partial \sigma}+\frac{\partial \eta}{\partial t}=0 \\
& \frac{\partial u D}{\partial t}+\frac{\partial u^{2} D}{\partial x}+\frac{\partial u \nu D}{\partial y}+\frac{\partial u \omega}{\partial \sigma}-f v D+g D \frac{\partial \eta}{\partial x}=-\frac{g D^{2}}{\rho_{0}} \int_{\sigma}^{0}\left(\frac{\partial \rho^{\prime}}{\partial x}-\frac{\rho^{\prime}}{D} \frac{\partial D}{\partial x} \frac{\partial \rho^{\prime}}{\partial \sigma^{\prime}}\right) d \sigma^{\prime}+\frac{\partial}{\partial \sigma}\left(\frac{K_{M}}{D} \frac{\partial u}{\partial \sigma}\right) \\
& \frac{\partial v D}{\partial t}+\frac{\partial u v D}{\partial x}+\frac{\partial v^{2} D}{\partial y}+\frac{\partial \nu \omega}{\partial \sigma}+f u D+g D \frac{\partial \eta}{\partial y}=-\frac{g D^{2}}{\rho_{0}} \int_{\sigma}^{0}\left(\frac{\partial \rho^{\prime}}{\partial y}-\frac{\rho^{\prime}}{D} \frac{\partial D}{\partial y} \frac{\partial \rho^{\prime}}{\partial \sigma^{\prime}}\right) d \sigma^{\prime}+\frac{\partial}{\partial \sigma}\left(\frac{K_{M}}{D} \frac{\partial v}{\partial \sigma}\right)
\end{aligned}
$$

Conservation equations for temperature and salinity:

$$
\begin{aligned}
& \frac{\partial T D}{\partial t}+\frac{\partial T u D}{\partial x}+\frac{\partial T \nu D}{\partial y}+\frac{\partial T \omega}{\partial \sigma}=\frac{\partial}{\partial \sigma}\left(\frac{K_{H}}{D} \frac{\partial T}{\partial \sigma}\right)+F_{T} \\
& \frac{\partial S D}{\partial t}+\frac{\partial S u D}{\partial x}+\frac{\partial S \nu D}{\partial y}+\frac{\partial S \omega}{\partial \sigma}=\frac{\partial}{\partial \sigma}\left(\frac{K_{H}}{D} \frac{\partial S}{\partial \sigma}\right)+F_{S}
\end{aligned}
$$

Barotropic mode depth-integrated continuity and momentum equations:

$$
\begin{aligned}
& \frac{\partial D U}{\partial x}+\frac{\partial D V}{\partial y}+\frac{\partial \eta}{\partial t}=0 \\
& \frac{\partial U D}{\partial t}+\frac{\partial U^{2} D}{\partial x}+\frac{\partial U V D}{\partial y}-\tilde{F}_{x}+f V D+g D \frac{\partial \eta}{\partial x}=\frac{\tau_{x}^{(s)}}{\rho}+\frac{\tau_{x}^{(b)}}{\rho}+G_{x}-\frac{g D}{\rho_{0}} \int_{-1}^{0} \int_{\sigma}^{0}\left(D \frac{\partial \rho^{\prime}}{\partial x}-\sigma^{\prime} \frac{\partial D \partial \rho^{\prime}}{\partial x \partial \sigma^{\prime}}\right) d \sigma^{\prime} d \sigma \\
& \frac{\partial V D}{\partial t}+\frac{\partial U V D}{\partial x}+\frac{\partial V^{2} D}{\partial y}-\tilde{F}_{y}+f U D+g D \frac{\partial \eta}{\partial y}=\frac{\tau_{y}^{(s)}}{\rho}+\frac{\tau_{y}^{(b)}}{\rho}+G_{y}-\frac{g D}{\rho_{0}} \int_{-1}^{0} \int_{\sigma}^{0}\left(D \frac{\partial \rho^{\prime}}{\partial y}-\sigma^{\prime} \frac{\partial D \partial \rho^{\prime}}{\partial y \partial \sigma^{\prime}}\right) d \sigma^{\prime} d \sigma
\end{aligned}
$$

\subsection{Surface and bottom boundary conditions}

1. The momentum, heat and salinity budget at the sea surface boundary are taken at $\sigma=0$ in the forms:

$\left.\frac{K_{M}}{D} \frac{\partial u}{\partial \sigma}\right|_{\sigma=0}=\frac{\tau_{x}^{(s)}}{\rho},\left.\quad \frac{K_{M}}{D} \frac{\partial v}{\partial \sigma}\right|_{\sigma=0}=\frac{\tau_{y}^{(s)}}{\rho}$.

$\left.\frac{K_{H}}{D} \frac{\partial T}{\partial \sigma}\right|_{\sigma=0}=\frac{Q_{T}}{\rho C_{p}}+\frac{C_{1}}{\rho C_{p}}\left(T^{*}-T\right)$

$\left.\frac{K_{H}}{D} \frac{\partial S}{\partial \sigma}\right|_{\sigma=0}=W_{s}+C_{2}\left(S^{*}-S\right)$.

The solar radiation, salt flux $W_{s}$ (from evaporation minus precipitation), as well as the momentum fluxes $\tau_{x}^{(s)}$ and $\tau_{y}^{(s)}$ (wind stress), are computed using monthly climatology ECMWF perpetual year forcing (see Fig. 5 for examples of solar radiation). The monthly evaporation rate $E$ was calculated from the ECMWF 1979-1993 6-hourly atmospheric data set and Reynolds monthly SST data (Reynolds and Smith, 1994), using the Kondo (1975) bulk formula.
The precipitation rate $P$ is obtained from the Jaeger (1976) monthly precipitation climatology.

$Q_{T}$, the total heat flux, is equal to upward heat loss minus solar radiation. The upward radiation imposed on the CYCOM model is the 10-day average upward heat flux diagnosed from the second year of the ALERMO run, while the upward heat flux imposed on the ALERMO model is from the eighth year of the OGCM climatological run.

Weak relaxation terms $C_{1}\left(T^{*}-T\right)$ and $C_{2}\left(S^{*}-S\right)$ are included in Eqs. (11) and (12) which act as further adjustments of the OGCM heat and salt fluxes to the ALERMO modelling area and, respectively, of the ALERMO fluxes to the CYCOM modelling area. In these terms, for CYCOM, $T^{*}$ and $S^{*}$ are the monthly average sea surface temperature and salinity from the second year of the ALERMO run, while for ALERMO they are taken from the eighth year of the OGCM perpetual year run. Thus, these terms help to maintain consistency among the three nested models. After sensitivity studies, $C_{2}$ has been set equal to $0.7 \mathrm{~m} /$ day. In both ALERMO and CYCOM, $C_{1}$ is set equal to $5 \mathrm{~W} /\left(\mathrm{m}^{2}{ }^{\circ} \mathrm{C}\right)$.

Linear interpolation between the monthly averages of the surface temperature $T^{*}$ and salinity $S^{*}$ generates systematic 


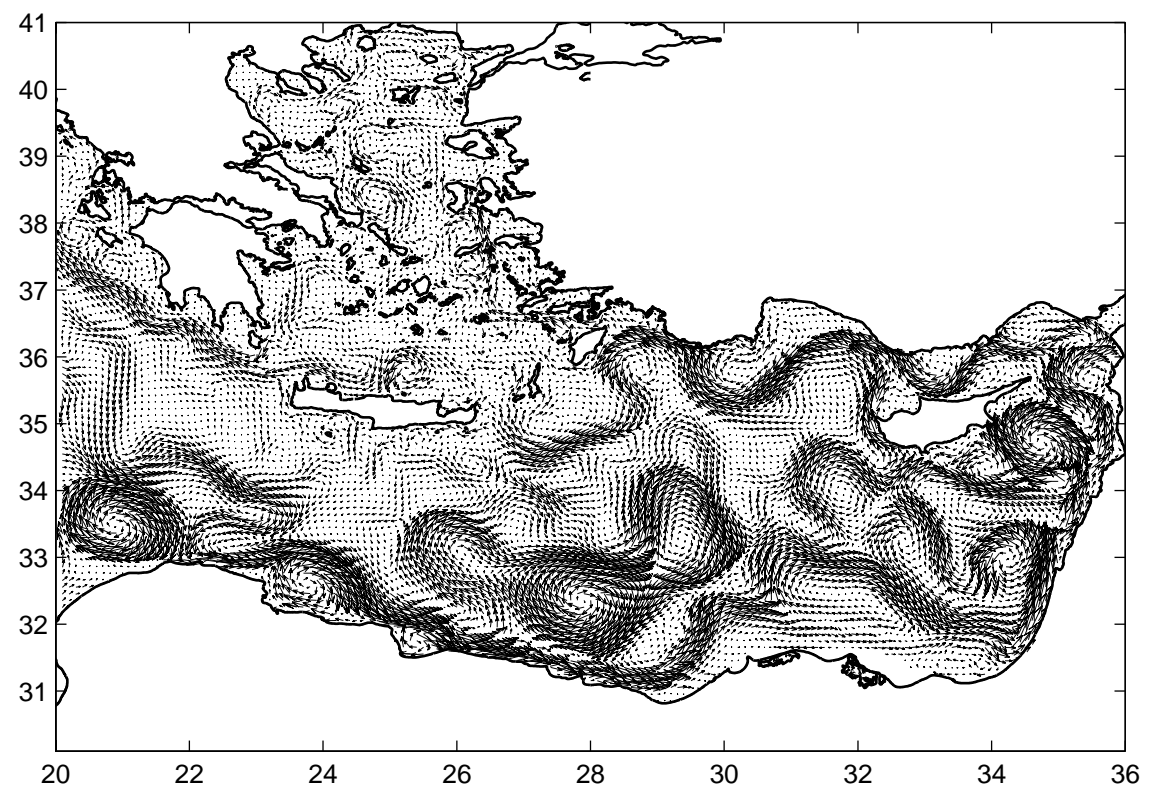

Fig. 6. ALERMO circulation at $30 \mathrm{~m}$, for August of the second year of the climatological run. errors, especially near their extreme values, while use of constant values for $T^{*}$ and $S^{*}$ for each month produces unacceptable oscillations in the computed fields after the end of each month. Therefore, we have followed the technique of Killworth (1996) to compute interpolants for the middle of each month, in such a way that linear interpolation of $T^{*}$ and $S^{*}$ between successive interpolants yields the monthly averages in the $T^{*}$ and $S^{*}$ database.

2. Sea bed momentum condition is applied at $\sigma=-1$ :

$$
\left.\frac{K_{M}}{D} \frac{\partial u}{\partial \sigma}\right|_{\sigma=-1}=\frac{\tau_{x}^{(b)}}{\rho},\left.\quad \frac{K_{M}}{D} \frac{\partial v}{\partial \sigma}\right|_{\sigma=-1}=\frac{\tau_{y}^{(b)}}{\rho},
$$

where the bottom friction is parameterized using the quadratic friction law,

$$
\left(\tau_{x}^{(s)}, \tau_{y}^{(s)}\right)=-\left.C \rho \sqrt{u^{2}+v^{2}}(u, v)\right|_{\sigma=0} .
$$

The dimensionless drag coefficient $C(x, y)$ is computed using the empirical relation $C(x, y)=\left[(1 / \kappa) \log \left(H / z_{0}\right)\right]^{-2}$, where $\kappa$ is the Von Karman constant and $z_{0}$ is the bottom roughness.

\subsection{Lateral boundary conditions and nesting}

Along the closed coastal boundaries, the depth-averaged normal velocity component is set to zero, $U_{n}=0$. Open boundaries create substantial computational difficulties in the modelling of a limited domain. In the present climatological simulation, we have a high resolution model domain with open boundaries, embedded in a coarse resolution model. The circulation in the coastal/shelf areas encompasses flow features of various spatial scales, particularly in open sea areas, such as the Cyprus shelf, which are influenced greatly by the mesoscale flow phenomena of the neighbouring open sea waters, in this case, the SE Levantine Basin. Therefore, it is very important that the nesting technique should allow the mesoscale features generated on the coarse model to influence the embedded high resolution model domain, simulating appropriate smaller scale flow features.

\subsubsection{Nesting CYCOM with the ALERMO model}

The Cyprus nested model has a 3-km grid spacing, with two open boundaries along the west and south sides (Fig. 4). The model is nested within the ALERMO model, which covers the whole eastern half of the Mediterranean Sea, with a coarser grid (about $6 \mathrm{~km}$ ), i.e. the nesting ratio is approximately $2: 1$. The nesting method that has been used is a passive, one way interaction (Spall and Holland, 1991), where the nesting provides for information to be passed along the open boundaries from the ALERMO coarse grid to the CYCOM high-resolution grid model. The successful nesting of the CYCOM model requires that the main flow features in the coarse grid must also be present in the high resolution grid.

In the beginning, the ALERMO data $(u, v, U, V, T, S)$ were extracted for each of the 10 days and were interpolated bilinearly to the open boundary points of the CYCOM model. Files containing all the necessary boundary data for a whole year have been constructed. Since the CYCOM model uses the same $30-\sigma$ levels as ALERMO, only horizontal bilinear interpolation is carried out along the boundaries. The description of the nesting procedures suggests that bathymetry along the boundaries is identical in both the ALERMO and CYCOM. To use the boundary data during the execution of the Cyprus model, two of these files are read every 10 days and for the following 10 days of the run, the boundary values in these files are interpolated to the current time. For example, starting 1 January, the files for 30 December and 10 January are read and the data in these files are interpolated until 

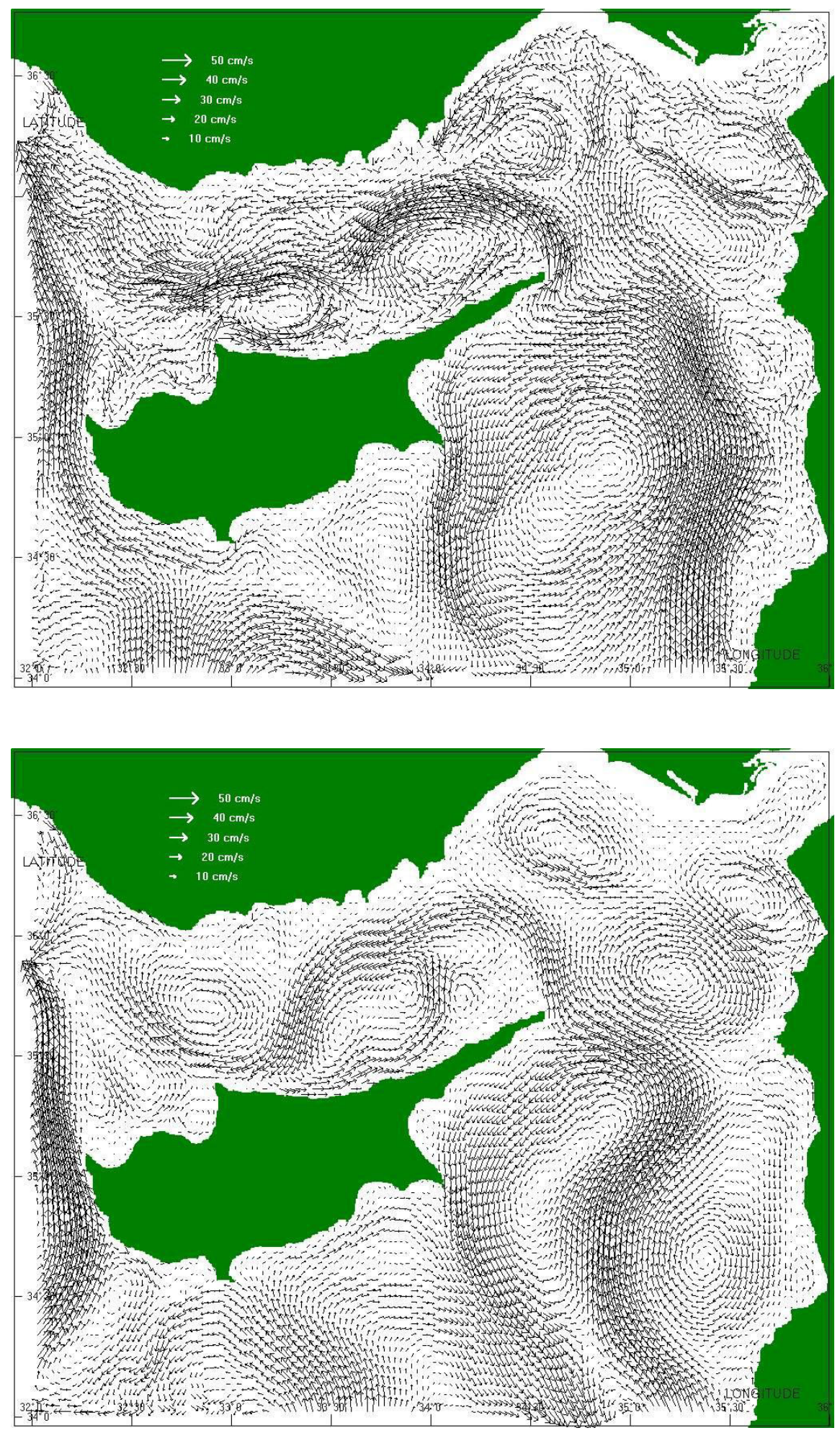

Fig. 7a. CYCOM circulation at $30 \mathrm{~m}$, for February of the second year of the climatological run.
Fig. 7b. CYCOM circulation at $30 \mathrm{~m}$, for April of the second year of the climatological run.
10 January is reached. Then, the files for 10 January and 20 January are read and are interpolated for the next 10 days, and so on.

The process of interpolating the coarse grid variables to obtain the open boundary conditions for the high resolution grid model does not conserve the fluxes of mass, heat, or momentum at the boundary between the two models. The fluxes through this boundary into the high resolution grid model will not be the same as the fluxes computed through the same boundary from the coarse grid variables. This is particularly important in the case of mass flux. When complete velocities are prescribed on the open boundaries, there 

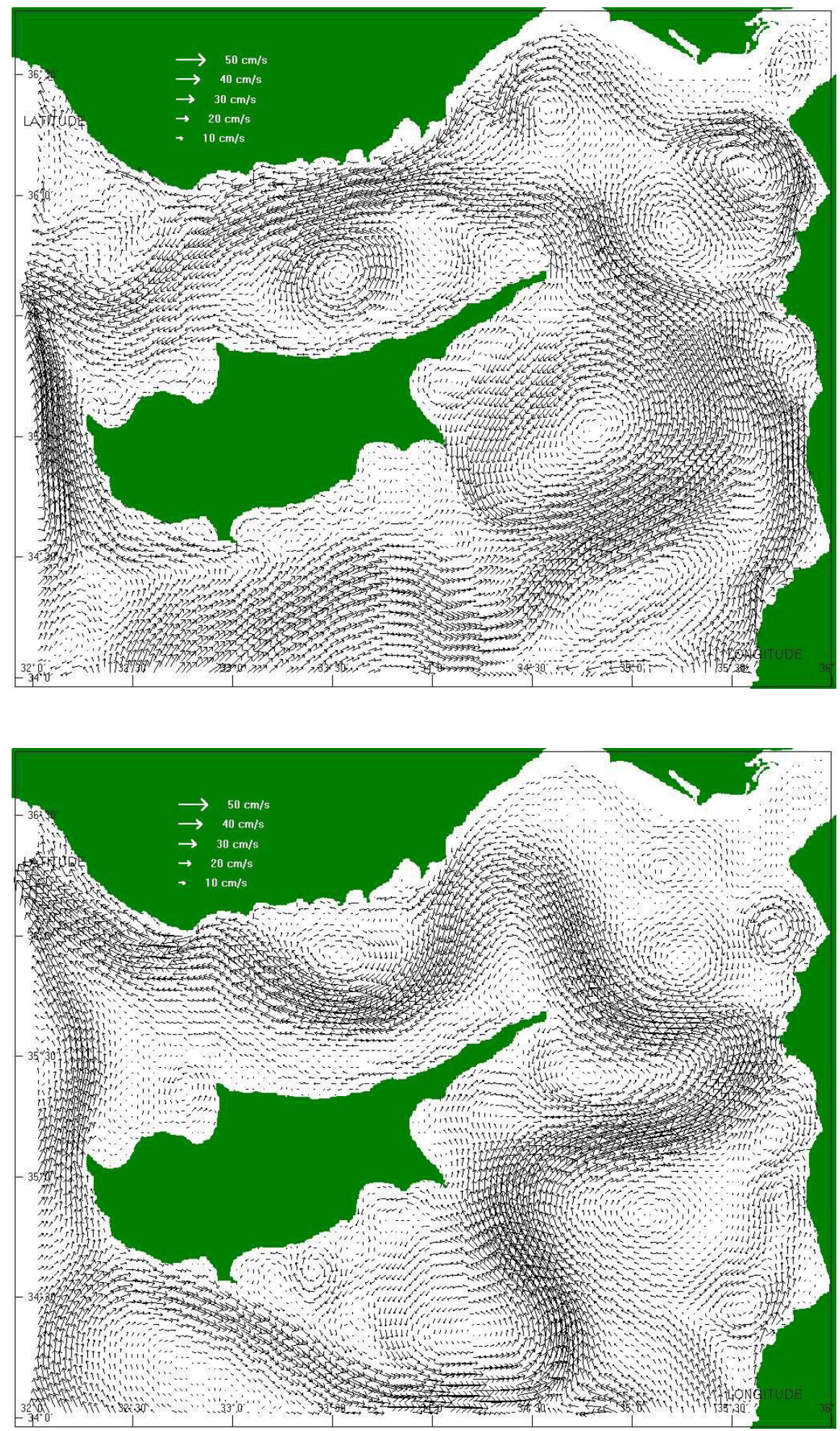

Fig. 7c. CYCOM circulation at $30 \mathrm{~m}$, for June of the second year of the climatological run.
Fig. 7d. CYCOM circulation at $30 \mathrm{~m}$ for August of the second year of the climatological run. is a small net volume flux into or out of the region, caused by round-off errors due to the interpolation from the coarse to the fine grid. Due to the small lateral extent of the region and the great water depths, this small imbalance produces very significant changes in surface elevation. To overcome this problem, the boundary values of velocities (barotropic and baroclinic) from ALERMO are corrected immediately after they are read, so that the total volume flux into the Cyprus domain through each of its open boundary segments is preserved (see the Appendix). The correction required is very small, generally less than $1 \mathrm{~mm} / \mathrm{s}$.

Along the south and west open sea boundaries, the Cyprus 


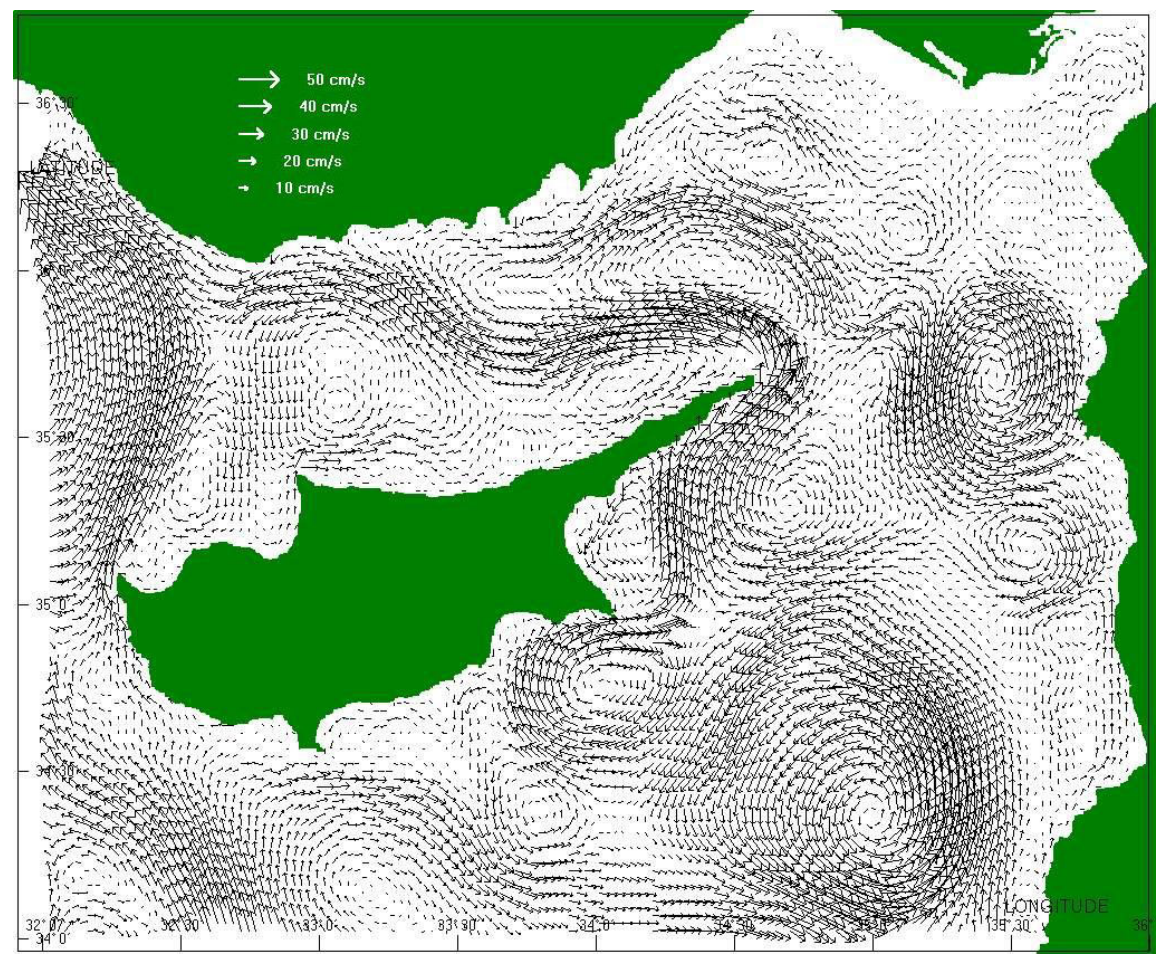

Fig. 7e. CYCOM circulation at $30 \mathrm{~m}$, for October of the second year of the climatological run. model is nested within the intermediate/regional ALERMO model, as follows:

A. The surface elevation is not nested. A zero-gradient boundary condition is imposed for cosmetic purposes but does not affect the computation.

B. For the normal component of the barotropic (depthaveraged) velocity, a mixed radiation/specification condition is applied in the form (Flather, 1988):

$$
\begin{aligned}
U_{n}^{\mathrm{CYCOM}}= & U_{m}^{\mathrm{ALERMO}} \\
& +\epsilon \sqrt{\frac{g}{H}\left(\eta^{\mathrm{CYCOM}}-\eta^{\mathrm{ALERMO}}\right)},
\end{aligned}
$$

where $\epsilon=1$ for an eastern or northern boundary and $\epsilon=-1$ for a western or southern boundary. This condition efficiently allows interior disturbances due to the mismatch between coarse and nested values to pass out through the lateral boundary.

C. The tangential component of the barotropic velocity is exactly specified by the interpolation of the coarse resolution model field to the finer model grid:

$$
U_{\text {tang }}^{\mathrm{CYCOM}}=U_{\text {tang }}^{\mathrm{ALERMO}}
$$

D. Both normal and tangential components of the baroclinic velocity are specified by the interpolation of the coarse resolution model field to the finer model grid

$$
u_{n}^{\mathrm{CYCOM}}=u_{n}^{\mathrm{ALERMO}}, \quad u_{\text {tang }}^{\mathrm{CYCOM}}=u_{\text {tang }}^{\mathrm{ALERMO}} .
$$

E. Advection on $T$ and $S$ into the region:

When $u_{n}$ is directed inwards to the fine grid region, $\left(u_{n}>0\right), T$ and $S$ at the boundary of the fine grid are specified by the coarse model solution:

$$
\begin{array}{ll}
T^{\mathrm{CYCOM}}=T^{\mathrm{ALERMO}}, & \left(u_{n}>0\right) \\
S^{\mathrm{CYCOM}}=S^{\mathrm{ALERMO}}, & \left(u_{n}>0\right)
\end{array}
$$

When $u_{n}$ is directed outwards, the boundary values are determined by simple advection from the interior:

$$
\begin{array}{ll}
\frac{\partial T}{\partial t}+u_{n} \frac{\partial T}{\partial n}=0, & \left(u_{n}<0\right) \\
\frac{\partial S}{\partial t}+u_{n} \frac{\partial S}{\partial n}=0, & \left(u_{n}<0\right) .
\end{array}
$$

\section{Results and discussion}

In general, the CYCOM and ALERMO subsurface circulation patterns (Figs. 6 and 7) demonstrate that both models successfully reproduce the well-known characteristics of the circulation in the study area, namely the Mid-Mediterranean Jet, Asia Minor Current and Lattakia cyclonic eddy. On top of this, the CYCOM model circulation patterns appear to be enriched in mesoscale structures, which are either missing or not well resolved by the coarse-intermediate resolution ALERMO model.

To obtain the circulation in the Cyprus and NE Levantine basins, the CYCOM has been integrated for 2 years. The fine grid of the model domain permitted simulation of the shelf 

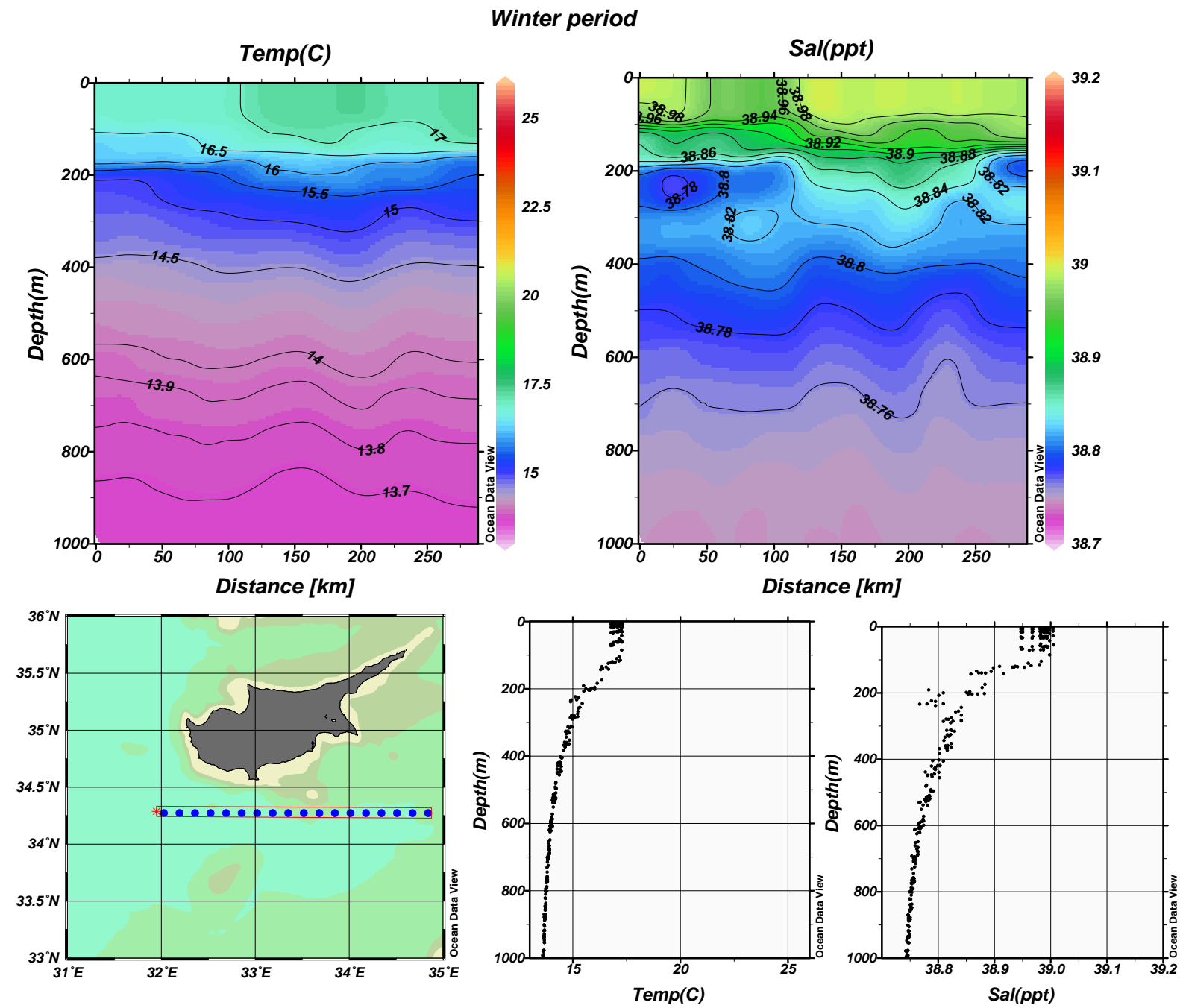

Fig. 8a. CYCOM temperature and salinity vertical structure and their composite profiles along the east-west section south of Cyprus, winter period of the second year of the climatological run.

and coastal flow features in more detail than previous computations. The results show several known features of the basin's general climatological circulation comprising several eddies and flow jets (Fig. 7).

The dominant flow features of the CYCOM domain were the strong MMJ, which is shown clearly to bifurcate $\mathrm{SW}$ of Cyprus, and the Lattakia cyclonic eddy. Both features appear almost throughout the entire period of the model simulations, except in the spring and autumn periods, where a significant spatial fluctuation was found. The main eastward branch of the MMJ is meandering south of Cyprus, then after passing Cyprus, the MMJ turns to the north, entering into the Lattakia Basin. The existence of the well developed Lattakia cyclonic eddy forces the MMJ to flow northward, initially closer to the coast of Lebanon, while further closer to the most northeastern edge of Cyprus, the Saint Andreas Cape, from where the MMJ enters the Cilician Basin. The secondary anticyclonic eddy which appears in the Lattakia Basin, close to the Lebanese coast, re-circulates part of the waters entering with the MMJ, through the southeastern boundary of the model domain. The description of the CYCOM results about the MMJ and of the Lattakia cyclonic eddy are mostly in agreement with the previous observational investigation in the area (Ozsoy et al., 1991; Zodiatis et al., 1998b; Krivisheya et al., 1998). Along the western coastline of Cyprus, the deflected northward branch of the MMJ generally flows northward, towards a convergence with the Asia Minor Current. Moreover, a small-scale anticyclonic eddy was found to be generated off the coast of Paphos (western coastline of Cyprus) during spring, inducing a southward flow within a few kilometres of that coast.

The flow pattern in the Cilician Basin is prevailed mainly by a cyclonic eddy circulating between the central northern coastline of Cyprus and the strong westward meandering current, which is known as the Asia Minor current (AMC). The $\mathrm{AMC}$ is known to transfer warm and saline waters from the NE Levantine towards the NW Levantine Basin (Ozsoy et al., 1989; Ozsoy et al., 1991; POEM group, 1992). In late 


\section{Summer period}
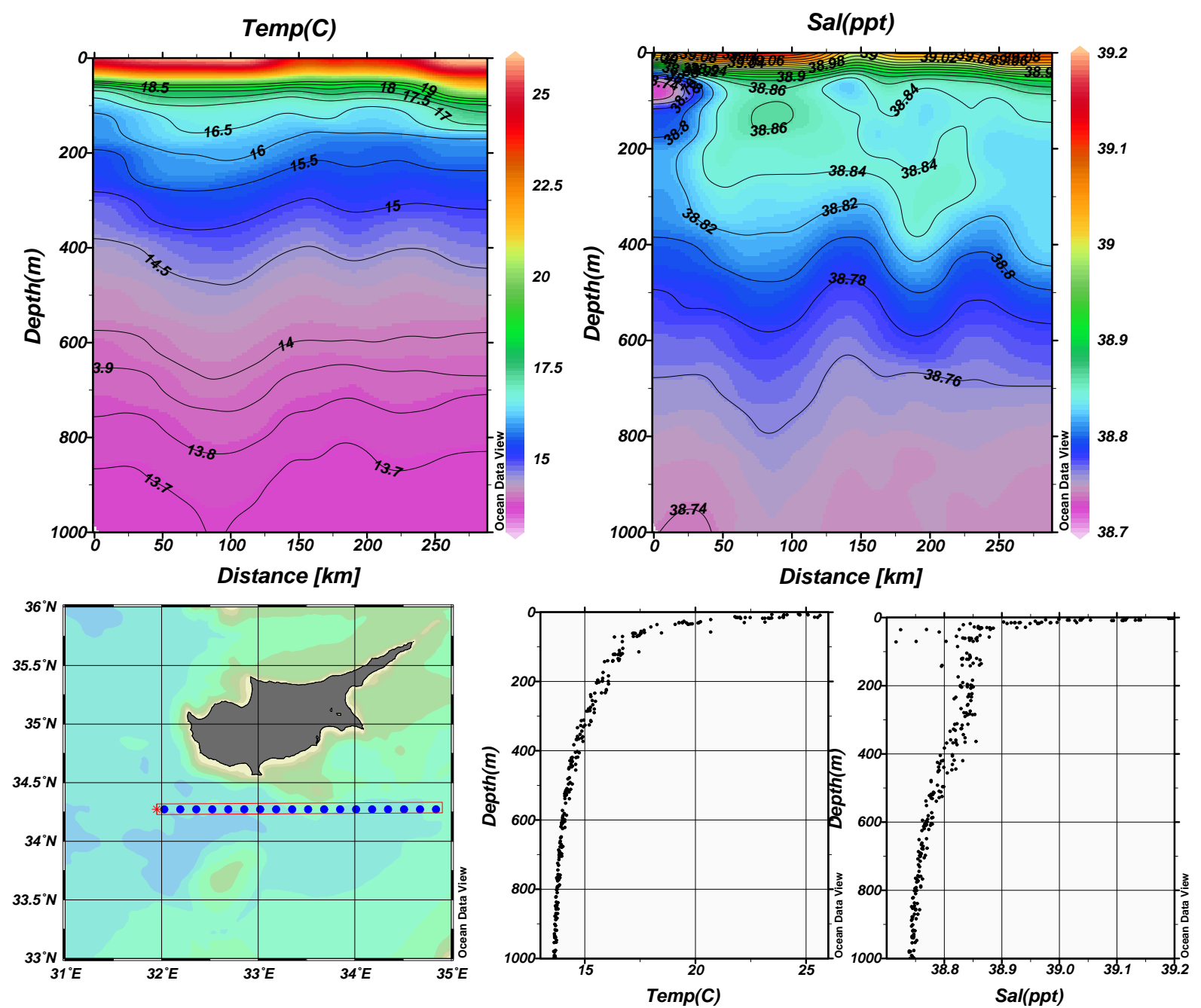

Fig. 8b. CYCOM temperature and salinity structure and their composite profiles along the east-west section south of Cyprus, summer period of the second year of the climatological run.

summer, between the AMC and the coastline of the Asia Minor, an anticyclonic eddy was generated, while smaller scale weak anticyclonic activities existed both west and east of the main cyclonic eddy of the Cilician Basin. The anticyclonic eddy, circulating at the entrance between the Lattakia and Cilician basins, forces the waters transferred by the MMJ to enter the Cilician Basin closer to the most northeastern edge of Cyprus, the Cape Saint Andreas. Previous investigation in the area (Ozsoy et al., 1991) shows that this anticyclonic eddy was capable of blocking the northward propagation of the MMJ into the Cilician Basin during certain periods. On the contrary, the present nested high resolution simulations of the CYCOM model give clear evidence that this anticyclonic eddy is not capable of blocking entirely the entry of the MMJ in the Cilician Basin and shows that the MMJ is continuously entering the Cilician Basin all year round.

It is of interest to mention that the main hydrographic features from the observational climatology were reproduced quite well by the CYCOM. The applied model was able to simulate the well-known upwelling phenomena that is found to occur along the southwestern coastline of Cyprus (Zodiatis et al., 1998a) in summer periods, due to the prevalence of the northwesterly winds. This feature is frequently apparent at this time of year from satellite SST images too. The CYCOM model produces a strip of cooler water along this coast during the early summer and a jet of cold water flowing towards the south or southeast, that is apparent in both the CYCOM and ALERMO models. The thermal structure of the waters, as shown along an east-west section south of Cyprus (Fig. 8), reveals that the water column responds to the seasonal variations of the surface fluxes at great depths, causing the winter homogenisation of the waters from the surface down to $100 \mathrm{~m}$ depth and the establishment of the strong summer thermocline down to $40-50 \mathrm{~m}$ depth. The thermohaline structure simulated by the CYCOM is of particular interest and shows similar water mass distribution, characterizing the study area, such as those found during the renewed in situ observational investigations of the SE Levantine Basin, 

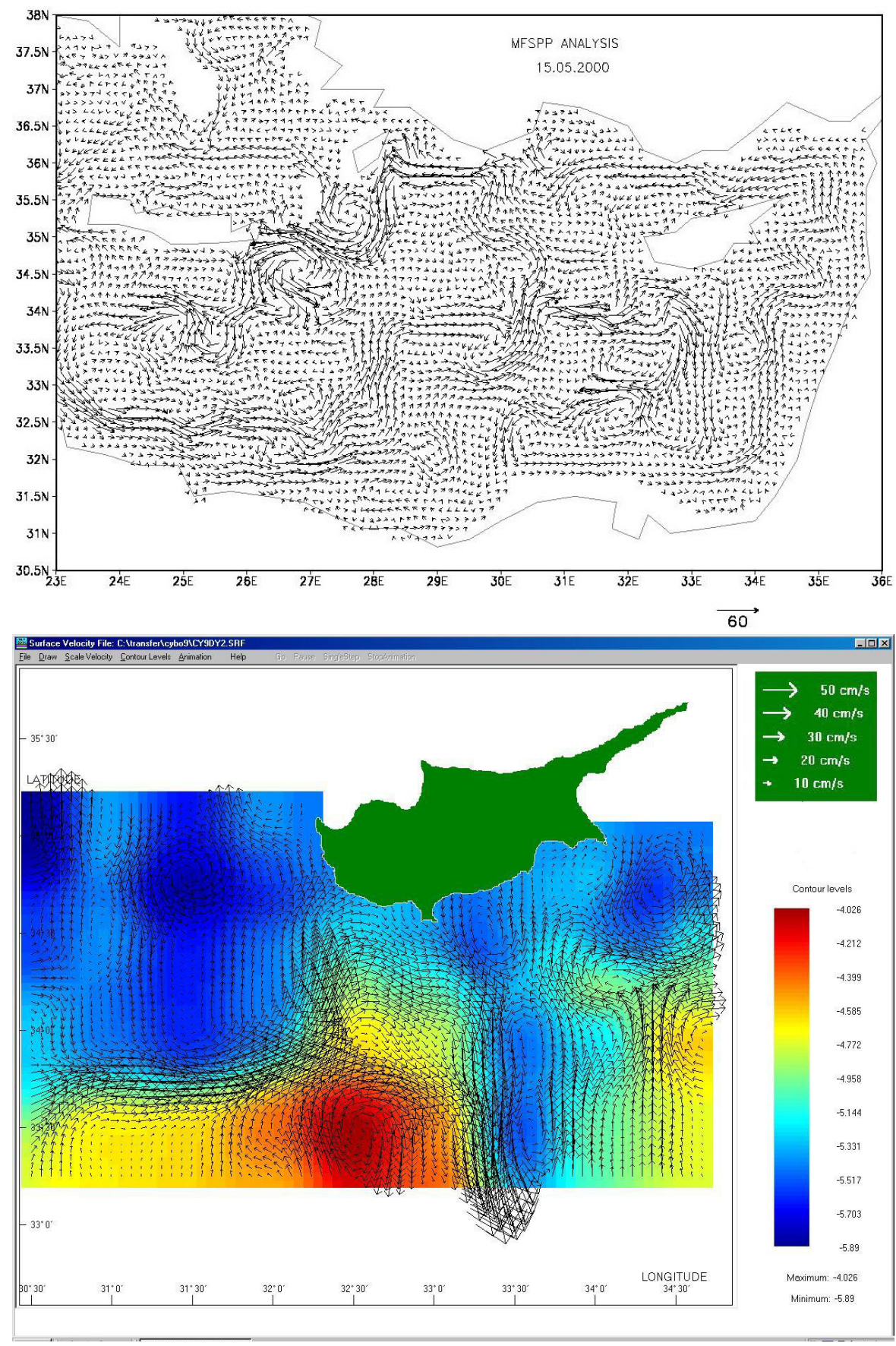

Fig. 9. Comparison of the circulation in the SE Levantine Basin at the $30 \mathrm{~m}$ depth, between: (a) the OGSM NRT operational forecasts and (b) the geostrophic flow (currents + dynamic height) derived from the CYBO project, both during the TOP period, May 2000. between 1995-2001 within the frame of the CYBO, CYCLOPS and MFSPP projects (Zodiatis et al., 1998a; Zodiatis et al., 2001; Manzella et al., 2001). The surface saline waters and the LIW were found to occupy the eastern part of the model domain, while the western part of the model domain is intruded by the MAW, which is transferred in the area by the MMJ. The salinity vertical profiles (Fig. 8) show that the MAW is well pronounced during the summer periods, while due to the winter mixing processes, these less saline surface and subsurface waters, having been mixed down to $100 \mathrm{~m}$ depth with the surrounding waters, are hardly evident in the area.

The intercomparison between the corresponding Figs. 6 and 7d, obtained, respectively, from ALERMO and CYCOM, shows a good consistency between the outputs of the two models, but at the same time, the finer grid of CYCOM has resolved a number of shelf-scale features that are present but not well resolved by the ALERMO grid. The 6-km grid of ALERMO is not adequate for these finer scale phenomena, as was suspected from our earlier estimate of the Rossby radius for the Cyprus Basin near the beginning of Sect. 3. This clearly demonstrates the advantage of the nest- 

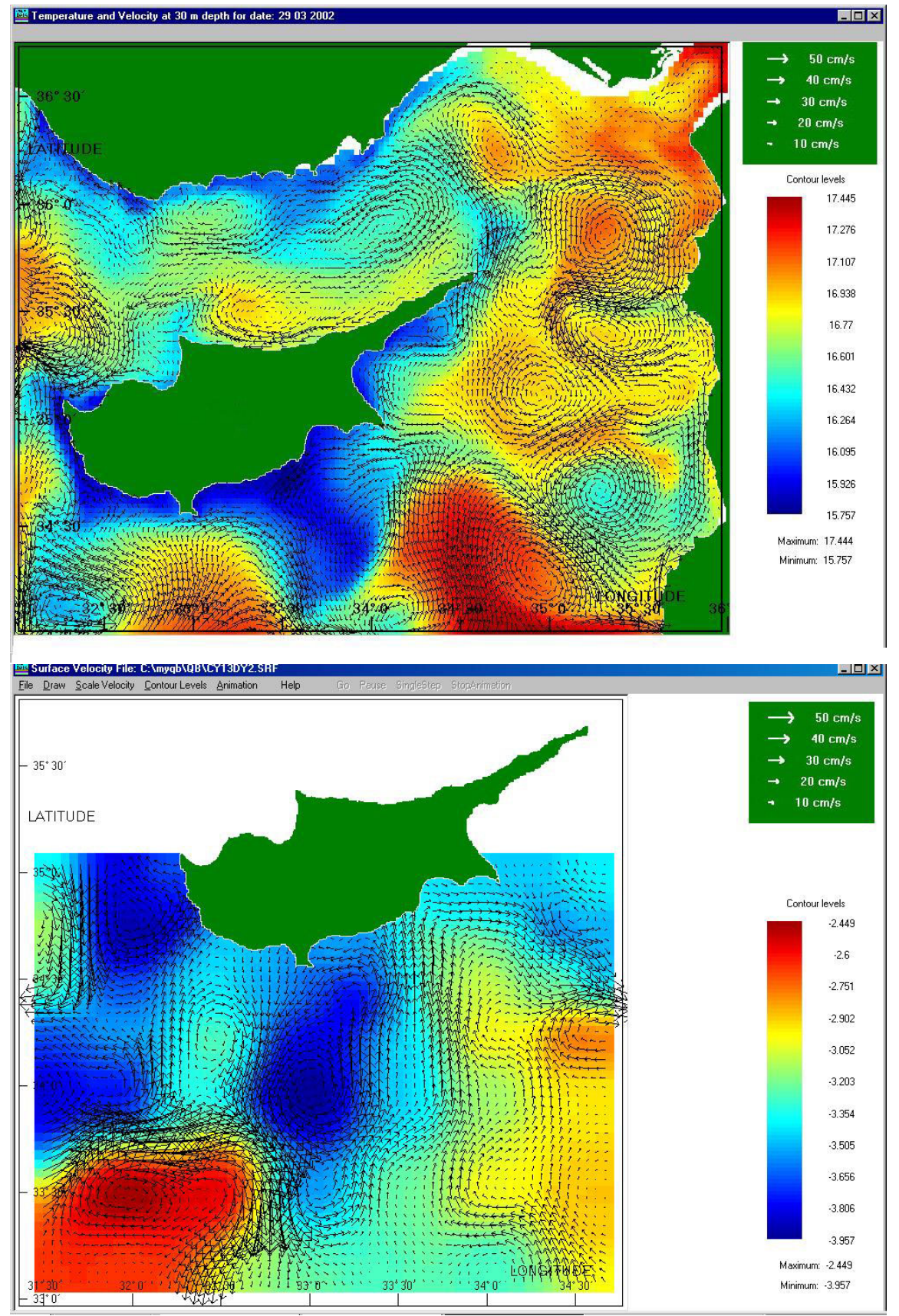

Fig. 10. Comparison of the circulation in the SE Levantine Basin at the $30 \mathrm{~m}$ depth, between: (a) the CYCOM NRT operational forecasts (currents + temperature at the $30 \mathrm{~m}$ ) for 29 March 2002 and (b) the geostrophic flow (geostrophic currents + dynamic height) derived from the CYBO project during March 2002. ing technique, allowing fine-scale features to be analyzed in regions where they may be important at relatively little extra computational cost.

Despite the improvements of the flow picture in the NE Levantine Basin, as a result of the application of the CYCOM model, it is still evident that the present simulations, based on the climatology of the ECMWF perpetual year surface forcing, were not able to resolve certain flow phenomena that were derived from the renewed investigations in the SE Levantine Basin, carried out by the CYBO project between 1995-2001. The overall picture of the circulation derived from the CYBO project reveals a detailed flow pattern in the neighbourhood of the southern coast of Cyprus and flow features, such as the Cyprus Basin Cyclonic Eddy and the warm core of the Cyprus eddy, which undergo strong seasonal and interannual fluctuations (Zodiatis et al., 2001).

It is expected that these additional observed flow features will be reproduced in the next phase of the MFS project, the MFSTEP-Mediterranean Forecasting System Towards Environmental Predictions, where the shelf/coastal models will be interfaced with 10-day actual real forecasts of atmospheric forcing parameters from operational weather centers, and data assimilation tools will be incorporated in order to initialize 10-day operational ocean forecasts. 
In view of the above, the comparison of the NRT operational forecasts, produced from the OGCM during the MFSPP TOP period in spring 2000, with the geostrophic flow, estimated from in situ data collected in the frame of the CYBO project during the same period, in May 2000, show similar flow features in the SE Levantine Basin (Fig. 9). In particular, a good agreement was found for the large-scale warm core Cyprus eddy, in accord with the POEM group (1992), attributed to the northern eddy composite, the Shikmona gyre, the meandering path of the MMJ and the enlarged north-south direction of cyclonic activity, all of which are located south of Cyprus.

Finally, it is worth mentioning that the recent developments and the upgrade of the CYCOM model to operational status, nested entirely within the ongoing operational forecasts of the MFSPP OGCM model, made it possible to produce daily operational forecasts on a weekly basis, using actual near-time surface forcing. The results of the CYCOM NRT ocean forecasts in the Cyprus model domain for March 2002 were in agreement with the general circulation pattern of the SE Levantine Basin, estimated from in situ data collected during the same period in the frame of the CYBO project (Fig. 10).

\section{Conclusions}

The response of the Cyprus and NE Levantine Basins, eastern Mediterranean Sea to MODB and ECMWF climatological forcing is studied using the Cyprus coastal ocean model (CYCOM), a shelf/coastal adaptation of the POM's primitive equations, nested entirely within the regional Aegean Levantine eddy resolving model (ALERMO). The main known climatological features of the local circulation are found to be reproduced quite well by the CYCOM model, particularly that of the MMJ and its bifurcation SW of Cyprus, and the cyclonic eddies in the Lattakia and Cilician basins. In addition, the model flow simulations show good agreement with those of the regional model that provides its lateral boundary data.

The modelling task reported here shows that development of an operational near real-time ocean forecasts in the coastal/shelf areas of the Mediterranean, which is the ultimate goal of the Mediterranean Forecasting System, can be achieved through the implementation of high resolution nested models, similar to that applied in the Cyprus shelf/coastal and open sea domain.

\section{Appendix A}

We require the following interpolation constraint for each section of the open boundary:

$$
\int_{l_{1}}^{l_{2}} \int_{-h^{\mathrm{COARSE}}}^{0} U_{n}^{\mathrm{COARSE}} d z d l=\int_{l_{1}}^{l_{2}} \int_{-h^{\mathrm{FINE}}}^{0} U_{n}^{\mathrm{INT}} d z d l \equiv \iint_{\Re} U_{n}^{\mathrm{INT}} d z d l,
$$

where $U_{n}^{\text {COARSE }}$ is the normal component of the coarse grid velocity field, $U_{n}^{\mathrm{INT}}$ is the normal component of the interpolated velocity vield, $\mathfrak{R}$ stands for the section of the boundary of the high resolution grid, and $h^{\mathrm{COARSE}}$ and $h^{\mathrm{FINE}}$ are the bathymetries of the coarse and fine-resolution grids.

To satisfy the constraint given by Eq. (A1), three steps are necessary:

Step 1: Calculate the original volume flux on the COARSE GRID:

$$
\int_{l_{1}}^{l_{2}} \int_{-h \text { COARSE }}^{0} U_{n}^{\mathrm{COARSE}} d z d l=V F^{\mathrm{COARSE}}\left(\mathrm{m}^{3} / \mathrm{s}\right)
$$

Step 2: Calculate the corresponding flux using INTERPOLATED velocities on the FINE GRID:

$$
\iint_{\mathfrak{R}} U_{n}^{\mathrm{INT}} d z d l=\int_{l_{1}}^{l_{2}} \int_{-h^{\mathrm{FNNE}}}^{0} U_{n}^{\mathrm{INT}} d z d l=V F^{\mathrm{INT}}\left(\mathrm{m}^{3} / \mathrm{s}\right) .
$$

Step 3:. Calculate the mean velocity correction:

$\Delta U=\frac{\left(V F^{\mathrm{INT}}-V F^{\mathrm{COARSE}}\right)}{S}(\mathrm{~m} / \mathrm{s})$,

where $S$ is the cross sectional area,

$S=\iint_{\mathfrak{R}} d l d z\left(\mathrm{~m}^{2}\right)$.

Then the interpolated normal velocity is corrected as follows:

$U_{n}^{\mathrm{CORR}}(x, y, z, t)=U_{n}^{\mathrm{INT}}(x, y, z, t) \Delta U \cdot F(x, y, z)$,

where $F$ can be any function whose average over the section is equal to 1 :

$\iint_{\mathfrak{R}} F(x, y, z) d l d z=S$.

$F(x, y, z)=1$ is the simplest choice and gives a uniform velocity correction over the whole section. An alternative choice is $F(x, y, z)$ proportional to $U_{n}^{\mathrm{INT}}(x, y, z, t)$, which leads to a corrected velocity everywhere proportional to the original interpolated velocity. The simplest way of writing this is

$U_{n}^{\mathrm{CORR}}(x, y, z, t)=U_{n}^{\mathrm{INT}}(x, y, z, t)\left(\frac{V F^{\mathrm{COARSE}}}{V F^{\mathrm{INT}}}\right)$.

Acknowledgements. This research has been carried out in the framework of the European Union MFSPP-Mediterranean Forecasting System Pilot Project, a EuroGOOS activity. We acknowledge the support of the European Commission's Marine Science and Technology Programme (MAST IV), contract MAS3-CT98-0171.

Topical Editor N. Pinardi thanks two referees for their help in evaluating this paper. 


\section{References}

Arakawa, A. and Lamb, V. R.: Computational design of the UCLA general circulation model, Methods in Computational Physics, v.17, Academic Press, 173-265, 1974.

Bignami, F., Marullo, S., Santoreli, R., and Schiano, M. E.: Longwave radiation budget in the Mediterranean sea, J. Geophys. Res., 100, 2501-2514, 1995.

Blumberg, A. F. and Mellor, G. L.: A description of a three-dimensional coastal ocean circulation model, in: ThreeDimensional Coastal Ocean Circulation Models, (Ed) Heaps, N. S., Coastal Estuarine Sci., vol. 4, AGU, Washington, D.C., 1-16, 1987.

Brenner, S.: Structure and evolution of warm core eddies in the eastern Mediterranean Levantine Basin, J. Geophys. Res., 94, 12593-12 602, 1989.

Budyko, M. I.: Atlas of the heat balance of the Earth, Glabnaia Geofiz. Observ., 1963.

Drakopoulos, P. G. and Lascaratos, A.: Modelling the Mediterranean Sea: climatological forcing, J. Marine Systems, 20, 157173, 1999.

EuroGOOS: The strategy for EuroGOOS, EuroGOOS Pupl., 1, 132, 1997.

Flather, R. A.: A numerical model investigation of tides and diurnal period continental shelf waves along Vancouver, J. Phys. Ocean., 18, 115-139, 1988.

Hellerman, S. and Rosenstein, M.: Normal wind stress ocer the word ocean with error estimates, J. Phys. Ocean., 13, 1093-1104, 1983.

Jaeger, L.: Monatskarte des Niederschlags fur die ganze Erde, Berichte des Deutschen Wetterdienstes, Band 18 (139), 1-38, 1976.

Killworth, P. D.: Time interpolation of forcing fields in ocean models, J. Phys. Ocean., 26, 136-143, 1996.

Kondo, J.: Air-sea bulk transfer coefficients in diabatic conditions, Boundary-Layer Meteorol. 9, 91-112, 1975.

Korres, G. and Lascaratos, A.: The Aegean-Levantine eddy resolving model (ALERMO): implementation and climatological runs, Rapp. Comm. int. Mer. Medit., 36, 70 p., 2001a.

Korres, G. and Lascaratos, A.: A climatological atmospheric forcing data set for use with general circulation models of the Mediterranean Sea, Rapp. Comm. int. Mer. Medit., 36, 71 p., 2001b.

Krivosheya, V. G., Titov, V. B., Ovchinnikov, I. M., Moskalenko, L. V., Yakubenko, V. G., Abousamra, F., Aboucora, I., and Boura, C.: The geostrophic circulation and currents structure in the eastern Mediterranean between the Syrian coast and Cyprus island in winter and summer seasons, Rapp. Comm. Int. Mer Medit., 35, 158 p., 1998.

Lardner, R. W. and Cekirge, H. M.: A new algorithm for threedimensional tidal and storm surge computations, App. Math.
Model. 12, 471-571, 1988.

Lascaratos, A. and Nittis, K.: A high resolution three-dimensional numerical study of intermediate water formation in the Levantine Sea, J. Geophys. Res., 103, 18 497-18 511, 1998.

Manzella, G. M. R., Cardin, V., Cruzado, A., Fusco, G., Gacic, M., Galli, C., Gasparini, G. P., Gervais, T., Kovacevic, V., Millot, C., Petit DeLa Villeon, L., Spaggiari, G., Tonani, M., Tziavos, C., Velasquez, Z., Walne, A., Zervakis, V., and Zodiatis, G.: EUsposored effort improves monitoring of circulation variability in the Mediterranean, EOS, 82, 43, 497-504, 2001.

Mellor, G. and Yamada, T.: Development of a turbulent closure model for geophysical fluid problems, Rev. Geophys., 20, 851$875,1982$.

Ozsoy, E., Hecht, A., and Unluata, U.: Circulation and hydrography of the Levantine Basin, Results of the POEM coordinated experiments 1985-1986, Progr. Oceanogr, 22, 125-170, 1989.

Ozsoy, E., Hecht, A., Unluata, U., Brenner, S., Oguz, T., Bishop, J., Latif, M. A., and Rozentraub, Z.: A review of the Levantine Basin circulation and its variability during 1985-1988, Dynamics Atm. Oceans, 15, 421-456, 1991.

Pinardi, N., Korres, G., Lascaratos, A., Roussenov, V., and Stanev, E.: Numerical simulation of the interannual variability of the Mediterranean Sea upper ocean circulation, Geophys. Res. Lett., 24, 4, 425-428, 1997.

POEM group: General circulation of the eastern Mediterranean Sea, Earth Sci. Rev., 32, 285-309, 1992.

Reynolds, R. W. and Smith, T. M.: Improved global sea surface temperature analyses, J. Climate, 7, 929-948, 1994.

Roussenov, V., Stanev, E., Artale, V., and Pinardi, N.: A seasonal model of the Mediterranean Sea general circulation, J. Geophys. Res., 100, 13 515-13 538, 1995.

Schlitzer, R.: Ocean Data View, http://www.awi-bremerhaven.de/ GEO/ODV, 2001.

Smagorinsky, J.: General circulation experiments with the primitive equations. Part I: the basic experiment, Monthly Weath. Rev., 91, 99-165, 1963.

Spall, M. A. and Holland, W. R.: A nested primitive equation model for oceanic applications, J. Phys. Oceanogr., 21, 205-220, 1991.

Zavatarelli, M. and Mellor, G. L.: A numerical study of the Mediterranean sea circulation, J. Phys. Oceanogr., 25, 1384-1414, 1995.

Zodiatis, G., Theodorou, A., and Demetropoulos, A.: Hydrography and circulation in the area south of Cyprus in late summer 1995 and in spring 1996, Oceanologica Acta, 21, 447-458, 1998a.

Zodiatis, G., Demetropoulos, A., and Theodorou, A. J.: A review of the circulation in the Cyprus Basin, eastern Mediterranean Levantine Basin, Rapp. Comm. int. Mer Medit., 35, 210 p., 1998 b.

Zodiatis, G., Manca, B., and Balopoulos, E.: Synoptic, seasonal and interannual variability of the warm core eddy south of Cyprus, SE Levantine Basin, Rapp. Comm. Int. Mer Medit., 36, 80 p., 2001. 